\title{
Thermal-Stress Effects and Enhanced Low Dose Rate Sensitivity in Linear Bipolar ICs o $\vec{\sim}$
}

M. R. Shaneyfelt, Senior Member IEEE, J. R. Schwank, Fellow IEEE, S. C. Witczak, Member IEEE, D. M. Fleetwood, Fellow IEEE, R. L. Pease, Member IEEE, P. S. Winokur, Fellow IEEE,

L. C. Riewe, and G. L. Hash, Member IEEE

\begin{abstract}
Pre-irradiation elevated-temperature stresses are shown to have a significant impact on the radiation response of a linear bipolar circuit. These thermal cycles can lead to part-topart variability in the radiation response of linear bipolar circuits packaged from the same wafer. In addition, it is also found that pre-irradiation elevated-temperature stress can have a significant impact on the enhanced low-dose-rate sensitivity (ELDRS) of LM111 voltage comparators. In some cases, the application of thermal stress eliminated ELDRS in the LM111s. Based on these data, it appears that there may be a connection between the mechanisms responsible for thermal-stress effects and ELDRS. Implications of these results on hardness assurance testing and mechanisms are discussed.
\end{abstract}

\section{INTRODUCTION}

Since the early 1990s, it has been known that some types $S_{\text {of bipolar devices exhibit enhanced low-dose-rate }}$ sensitivity (ELDRS) at low electric fields [1]-[7]. In addition, high-dose-rate irradiation followed by room temperature annealing does not accurately estimate the low-dose-rate response in many types of bipolar devices [1], [5]. This is in contrast to MOS devices where the response of devices following higher-rate irradiations plus anneals can typically match device response following lower dose-rate irradiations [8], [9]. ELDRS in NPN transistors has been attributed primarily to increased positive oxide-trap charge buildup in the isolation oxide overlying the base-emitter junction [7], [10]. This charge enhances the surface recombination rate in the p-base region. On the other hand, lateral and substrate PNP transistors are primarily affected by increased interfacetrap charge buildup in the thick isolation oxide over the emitter-base region [6], [11]. In most cases, ELDRS effects have been shown to be more important for lateral or substrate PNP transistors than for NPN transistors [4]. In fact, Johnston and co-workers [4] showed that the relative damage at low dose rates $\left(<0.01 \mathrm{rad}\left(\mathrm{SiO}_{2}\right) / \mathrm{s}\right)$ for junction-isolated linear processes could be greater than a factor of two larger in linear

Manuscript received July 25,2000 . This work was supported by the United States Department of Energy and the by the Defense Threat Reduction Agency through its Radiation Tolerant Microelectronics Program. Sandia is a multiprogram laboratory operated by Sandia Corporation, a Lockheed Martin Company, for the United States Department of Energy under Contract DE-AC04-94AL85000.

M. R. Shaneyfelt, J. R. Schwank, S. C. Witczak, L. C. Riewe, P. S. Winokur, and G. L. Hash are with Sandia National Laboratories, Albuquerque, New Mexico 87185-1083 USA (telephone: 505-844-6137, email: shaneymr@sandia.gov).

R. L. Pease is with RLP Research, Albuquerque, New Mexico 87122

D. M. Fleetwood is with Vanderbilt University, Nashville, TN 37235 bipolar circuits dominated by PNP transistor response than in those dominated by NPN transistor response.

During the same time period, it was demonstrated that the radiation response of some CMOS technologies could change dramatically if devices were exposed to a pre-irradiation elevated-temperature stress (PETS), for example burn-in following packaging [12]-[14]. PETS effects were shown to be associated with a thermally activated process that is bias independent, at least for the devices examined to date. While the mechanisms responsible for the PETS effect are not well understood, it has been shown that a pre-irradiation burn-in can cause an increase in positive oxide-trap charge buildup and a decrease in interface-trap charge buildup in gate and field oxides. More recently [15], [16], it has been shown that some linear bipolar technologies are also sensitive to burn-in. The mechanisms for the PETS effect for linear bipolar technologies appear to be qualitatively similar to those of the CMOS technologies.

More recently, J. Krieg et al., [17] evaluated the irradiation response of packaged bipolar linear comparators (LM111s) from a single wafer lot at both high and low dose rates. The data showed an apparent bimodal distribution in the irradiation response not only across the wafer lot, but also across a given wafer. For example, the input bias current of some LM111s taken from a given wafer degraded to $-200 \mathrm{nA}$ at $100 \mathrm{krad}\left(\mathrm{SiO}_{2}\right)$, while others degraded to $\sim 1000 \mathrm{nA}$. The cause of the bimodal distribution was traced to differences in the radiation response of the LM111 substrate PNP input transistors. While the reason for the difference in radiation response of the input bias transistors was not identified, we note that some bipolar linear comparators have previously been shown to be sensitive to PETS and ELDRS [4], [15].

In this work, we explore possible connections between PETS and ELDRS effects in linear bipolar circuits. Specifically, we focus on the LM111 voltage comparator. This was accomplished by closely controlling all the thermal cycles (before, during, and after packaging) that LM111 die are exposed to prior to irradiation. LM111 die were subjected to a range of pre-irradiation elevated temperature stresses and packaged at room temperature. The packaged devices were irradiated at high and low dose rates, and devices irradiated at high dose rates were annealed at room temperature. These data suggest a connection between ELDRS and PETS effects. Finally, possible mechanisms and hardness assurance issues are discussed. 


\section{EXPERIMENTAL DETAILS}

\section{A. Devices}

LM111 voltage comparator die were taken from a single wafer lot of 25 four-inch wafers supplied by National - Semiconductor from their United Kingdom bipolar linear fabrication line. Note that this is the same wafer lot used in a prior study of ELDRS in LM111s [17]. Unless otherwise indicated, all the data shown in this work are for die taken from the same wafer.

\section{B. Thermal Cycles}

Die were subjected to unbiased PETS at 100, 175 and $250^{\circ} \mathrm{C}$ for 0.25 to 1000 hours using Delta Design ovens. These ovens are capable of heating samples up to $315^{\circ} \mathrm{C}$. No attempt was made to control the ambient (used room ambient) in the oven during the thermal cycles. Die were placed in Pyrex dishes prior to being placed in the oven. Following elevated temperature stress, die were packaged in 14-pin DIPs. During packaging, the die were not subjected to additional thermal cycles. The die were attached to the packages at room temperature using a thermoplastic that cures at room temperature, and the lids were attached with tape. In this paper, we show only irradiation data for the $175^{\circ} \mathrm{C}$ elevated temperature stress. Qualitatively similar results were observed for the other elevated stress temperatures.

\section{Radiation Source}

Packaged devices (in general, three devices per irradiation and anneal condition) were irradiated with all pins shorted at dose rates of $0.01,0.1$, and $50 \mathrm{rad}\left(\mathrm{SiO}_{2}\right) / \mathrm{s}$. The 0.01 , and $0.1 \mathrm{rad}\left(\mathrm{SiO}_{2}\right) / \mathrm{s}$ irradiations were performed using a Cs-137 Shepherd Cell, and the $50 \mathrm{rad}\left(\mathrm{SiO}_{2}\right) / \mathrm{s}$ irradiations were performed using a Nordion Co-60 Gammacell 220. All irradiations were performed at room temperature. The devices were irradiated to $100 \mathrm{krad}\left(\mathrm{SiO}_{2}\right)$ in steps. After irradiation, devices were annealed at room temperature with all pins shorted.

\section{Measurements}

Packaged LM111s were characterized using a LTS2020 Linear IC tester manufactured by Analog Devices. All standard parametrics were measured, including input bias and offset current, offset voltage, and power supply currents. While we did not characterize the electrical response of the LM111s at the die level prior to PETS, all packaged parts indicated that the electrical response was not altered by the various thermal cycles. There was no significant difference in the pre-irradiation electrical measurements of the LM111s for the different PETS treatments. Also, a number of LM111 die (controls) were packaged without being exposed to thermal cycles before or during packaging, and their electrical response was essentially identical (within part-to-part variation) to the electrical response of LM111 die expose to PETS before packaging.

\section{EXPERIMENTAL RESULTS}

A recent study of ELDRS in packaged LM111s reported a bimodal distribution in the radiation response at high and low dose rates [17]. Hence, it seemed prudent to first determine if PETS effects could in fact account for this apparent bimodal distribution. The devices in [17] had been exposed to several thermal cycles (during and after packaging) before being irradiated. In this study, three die from each of 15 wafers were packaged without being exposed to PETS. The devices were then irradiated with all pins shorted at a dose rate of $50 \mathrm{rad}\left(\mathrm{SiO}_{2}\right) / \mathrm{s}$. We plot the radiation-induced changes in input bias current $\left(\mathrm{I}_{\mathrm{B}+}\right)$ for the LM111s versus total dose in Figure 1. Again, in the LM111, the input bias current is essentially the base current of the substrate PNP input transistor. Note that we are actually plotting the absolute value of $\mathrm{I}_{\mathrm{B}+}$, as we do throughout the paper. The shaded region on the figure represents the range in $\mathrm{I}_{\mathrm{B}+}$ observed in [17] at $100 \mathrm{krad}\left(\mathrm{SiO}_{2}\right)$ for equivalent irradiation conditions. For our devices, the $\mathrm{I}_{\mathrm{B}+}$ increases from $25.9 \pm 3 \mathrm{nA}$ preirradiation to $230 \pm 27 \mathrm{nA}$ at $50 \mathrm{krad}\left(\mathrm{SiO}_{2}\right)$, and the increase in $\mathrm{I}_{\mathrm{B}+}$ appears to saturate above $30 \mathrm{krad}\left(\mathrm{SiO}_{2}\right)$. We observe no bimodal distribution in the irradiation induced changes in $\mathrm{I}_{\mathrm{B}+}$, and the part-to-part variation (denoted by the error bars) is significantly smaller than the range of bimodal distribution reported in [17].

The lack of variation in the radiation response of devices that have not received any PETS suggests that the bimodal distribution in [17] may have been caused by the PETS those parts received during packaging. Indeed, through the remainder of this study, we have used this as a working hypothesis. However, we must point out that we cannot rule out the possibility that another process might be contributing to the bimodal distribution in irradiation response reported in [17]. For example, temperature cycles during the normal packaging process can also induce changes in the mechanical stress on the die. In contrast, the packaging procedure in this work should not impact the mechanical stress of the die nearly as much (if any), since all bonding was performed at room temperature. This minimizes stresses associated with differences in thermal expansion coefficients between the die and package carrier. In any case, the demonstration in Figure 1 that we can package LM111 die without inducing a significant part-to-part variation in radiation response indicates these are good devices to use for exploring a possible connection between PETS and ELDRS effects.

We start by examining the radiation response of LM111s that were not subjected to a pre-irradiation elevated temperature stress as a function of dose rate. Figure 2 is a plot of the positive input bias current $\left(I_{B+}\right)$ versus dose for devices irradiated at $0.01,0.1$, and $50 \mathrm{rad}\left(\mathrm{SiO}_{2}\right) / \mathrm{s}$. For the $50 \mathrm{rad}\left(\mathrm{SiO}_{2}\right) / \mathrm{s}$ irradiation, $\mathrm{I}_{\mathrm{B}+}$ increases from $\sim 24 \mathrm{nA}$ before irradiation to $\sim 200 \mathrm{nA}$ at $100 \mathrm{krad}\left(\mathrm{SiO}_{2}\right)$, and the increase in $\mathrm{I}_{\mathrm{B}+}$ appears to saturate, consistent with the data in Figure 1. For the $0.1 \mathrm{rad}\left(\mathrm{SiO}_{2}\right) / \mathrm{s}$ irradiation, we see an increase in $\mathrm{I}_{\mathrm{B}+}$ up to $315 \mathrm{nA}$ at $10 \mathrm{krad}\left(\mathrm{SiO}_{2}\right)$. Between 10 and 


\section{DISCLAIMER}

This report was prepared as an account of work sponsored by an agency of the United States Government. Neither the United States Government nor any agency thereof, nor any of their employees, make any warranty, express or implied, or assumes any legal liability or responsibility for the accuracy, completeness, or usefulness of any information, apparatus, product, or process disclosed, or represents that its use would not infringe privately owned rights. Reference herein to any specific commercial product, process, or service by trade name, trademark, manufacturer, or otherwise does not necessarily constitute or imply its endorsement, recommendation, or favoring by the United States Government or any agency thereof. The views and opinions of authors expressed herein do not necessarily state or reflect those of the United States Government or any agency thereof. 


\section{DISCLAIMER}

Portions of this document may be illegible in electronic image products. Images are produced from the best available original document. 
$33 \mathrm{krad}\left(\mathrm{SiO}_{2}\right), \mathrm{I}_{\mathrm{B}+}$ appears to level off. However, at total doses above $33 \mathrm{krad}\left(\mathrm{SiO}_{2}\right)$, a second rapid buildup in $\mathrm{I}_{\mathrm{B}+}$ occurs, and $\mathrm{I}_{\mathrm{B}+}$ increases to $900 \mathrm{nA}$ at $100 \mathrm{krad}\left(\mathrm{SiO}_{2}\right)$. For the $0.01 \mathrm{rad}\left(\mathrm{SiO}_{2}\right) / \mathrm{s}$ irradiation, $\mathrm{I}_{\mathrm{B}+}$ continues to increase with dose up to a peak current of $1500 \mathrm{nA}$ at $70 \mathrm{krad}\left(\mathrm{SiO}_{2}\right)$, after which we see a slight decrease with increasing dose. The large difference in $\mathrm{I}_{\mathrm{B}_{+}}$between the low- and high-dose-rate irradiations suggests that these LM111s exhibit an ELDRS effect, consistent with previously reported work $[4,18,19]$. To illustrate this point, in Figure 3 we compare the relative damage factor (determined at $10 \mathrm{krad}\left(\mathrm{SiO}_{2}\right)$ as was done in [4], [18] to avoid nonlinearities that can occur at higher dose levels) for the LM111s studied in this work to LM111 data reported in [4], [18], and note excellent agreement. This was surprising since, to our knowledge, there was no attempt to control the thermal cycles the devices were exposed to in [4], [17], [18].

We performed several experiments to more systematically determine whether PETS may affect ELDRS in LM111s. In Figure 4 we plot $I_{B+}$ as a function of dose for LM111s subjected to a $175^{\circ} \mathrm{C}$ pre-irradiation stress for stress times up to 1000 hours. Also shown are the results for LM111s that were not subjected to elevated temperature stress. The elevated temperature stress causes a reduction in the increase in post-irradiation $I_{B+}$, with longer stress times producing smaller increases. These data clearly show a PETS effect for the LM111s irradiated at $50 \mathrm{rad}\left(\mathrm{SiO}_{2}\right) / \mathrm{s}$. After irradiating to $100 \mathrm{krad}\left(\mathrm{SiO}_{2}\right)$, the PETS leads to a decrease in the postirradiation $\mathrm{I}_{\mathrm{B}+}$ by approximately $33 \%$ for devices stressed for 1000 hours as opposed to devices without a thermal stress.

Because we see a PETS effect at $50 \mathrm{rad}\left(\mathrm{SiO}_{2}\right) / \mathrm{s}$, one might also expect a PETS effect at lower dose rates. The results of Figure 5 clearly show this is the case. Here we plot $\mathrm{I}_{\mathrm{B}+}$ as a function of dose at a rate of $0.1 \mathrm{rad}\left(\mathrm{SiO}_{2}\right) / \mathrm{s}$ for LM111s subjected to $175^{\circ} \mathrm{C}$ pre-irradiation stresses from 0 to 1000 hours. As the stress time is increased, we observe a decrease in the post-irradiation $\mathrm{I}_{\mathrm{B}+}$. At $100 \mathrm{krad}\left(\mathrm{SiO}_{2}\right)$, PETS reduces the change in $\mathrm{I}_{\mathrm{B}+}$ by approximately $62 \%$, nearly twice as much as for the $50 \mathrm{rad}\left(\mathrm{SiO}_{2}\right) / \mathrm{s}$ irradiation. These data are consistent with the trends observed at a still lower dose rate of $0.01 \mathrm{rad}\left(\mathrm{SiO}_{2}\right) / \mathrm{s}$ (not shown).

Examining the data for total doses $\leq 50 \mathrm{krad}\left(\mathrm{SiO}_{2}\right)$ in Figures 4 and 5 , it is evident that the difference between $\mathrm{I}_{\mathrm{B}+}$ at the high and low dose rates is being reduced or eliminated as the PETS time is increased. For higher total doses, the devices irradiated at $0.1 \mathrm{rad}\left(\mathrm{SiO}_{2}\right) / \mathrm{s}$ still show a rapid increase in $\mathrm{I}_{B+}$ with total dose independent of the PETS time. The impact of the $175^{\circ} \mathrm{C}$ PETS on the dose rate response of the LM111 is more clearly illustrated in Figure 6, where we plot the irradiation data following a 1000-hour stress. At total doses up to $10 \mathrm{krad}\left(\mathrm{SiO}_{2}\right)$, there is almost no difference in the post-irradiation $\mathrm{I}_{\mathrm{B}+}$ with dose rate, in contrast to the data for the samples with no PETS, which is most clearly seen by comparing Figures 2 and 6 . There is nearly a factor of 5 separation in the $10 \mathrm{krad}\left(\mathrm{SiO}_{2}\right)$ data in Figure 2 (no PETS), but very little difference in the $10 \mathrm{krad}\left(\mathrm{SiO}_{2}\right)$ data of Figure 6 $\left(1000 \mathrm{~h}, 175^{\circ} \mathrm{C}\right.$ PETS). The absence of ELDRS after PETS continues in Figure 6 for the 0.1 and $50 \mathrm{rad}\left(\mathrm{SiO}_{2}\right) / \mathrm{s}$ data up to $50 \mathrm{krad}\left(\mathrm{SiO}_{2}\right)$. At higher doses, there is still a significant difference in the $I_{B+}$ at low and high dose rates. Now recall that differences in $I_{B+}$ as a function of dose rate at $10 \mathrm{krad}\left(\mathrm{SiO}_{2}\right)$ were used to calculate the relative damage numbers in Figure 3. Had the post-PETS data of Figure 6 been used at this dose, the conclusion would have been that these devices did not exhibit a significant ELDRS effect! Hence, we conclude that pre-irradiation temperature cycles can profoundly alter the low-dose-rate sensitivity of these LM111s.

Historically, ELDRS has been referred to as a true dose rate effect. In other words, device response following lowerdose-rate irradiations could not be matched by higher-doserate irradiations and equivalent anneals. We now consider whether the differences in $I_{B+}$ at high total doses in Figure 6 are (1) a true dose rate effect, (2) a simple time-dependent effect, due to the longer times associated with the low-doserate irradiation, or (3) a combination of both types of effects. To address this question, the devices irradiated at $50 \mathrm{rad}\left(\mathrm{SiO}_{2}\right) / \mathrm{s}$ were annealed at room temperature with all pins grounded for times up to $10^{6} \mathrm{~s}$ (which is an equivalent time to $100 \mathrm{krad}\left(\mathrm{SiO}_{2}\right)$ irradiation at $\left.0.1 \mathrm{rad}\left(\mathrm{SiO}_{2}\right) / \mathrm{s}\right)$ [20], [21]. The results are shown in Figure 7, where $I_{B+}$ is plotted as a function of irradiation and anneal time for the 0.1 and $50 \mathrm{rad}\left(\mathrm{SiO}_{2}\right) / \mathrm{s}$ irradiations for $\mathrm{LM} 111 \mathrm{~s}$ subjected to a $175^{\circ} \mathrm{C}$, 100 -hour stress. At $2000 \mathrm{~s}$, the $50 \mathrm{rad}\left(\mathrm{SiO}_{2}\right) / \mathrm{s}$ irradiation is completed, and the room temperature anneal starts. For the first $\sim 24$ hours of the anneal, we see little to no change in $I_{B+}$ (this is true for all devices irradiated at $50 \mathrm{rad}\left(\mathrm{SiO}_{2}\right) / \mathrm{s}$, independent of thermal stress), after which we see a significant increase in $I_{B+}$ continuing for $10^{6} \mathrm{~s}$. At $10^{6} \mathrm{~s}, \mathrm{I}_{\mathrm{B}+}$ increases to the same level as the LM111s that were irradiated at $0.1 \mathrm{rad}\left(\mathrm{SiO}_{2}\right) / \mathrm{s}$. Based on these results, we can draw two potential conclusions. First, the delay in any significant change in $\mathrm{I}_{\mathrm{B}+}$ during the first 24 hours may indicate that these devices have a latent interface-trap charge buildup similar to that observed for MOS devices [22], [23]. We note that others have also suggested the possibility of delayed interface-trap charge buildup near midgap to explain the ELDRS response in PNP transistors [6], [11]. Second, the $175^{\circ} \mathrm{C} 100$-hour stress appears to have eliminated any true dose-rate effects that may have existed in these devices.

It is important to point out that most previously published data on LM111s suggesting ELDRS did not account for postirradiation anneals [4], [18], [19]. Thus, one might wonder if LM111s ever exhibit "true" dose rate sensitivity. We address this issue by comparing the $50 \mathrm{rad}\left(\mathrm{SiO}_{2}\right) / \mathrm{s}$ results, the $50 \mathrm{rad}\left(\mathrm{SiO}_{2}\right) / \mathrm{s}$ plus anneal results, and the $0.1 \mathrm{rad}\left(\mathrm{SiO}_{2}\right) / \mathrm{s}$ results in Figure 8. Here we plot $\mathrm{I}_{\mathrm{B}+}$ as a function of the $175^{\circ} \mathrm{C}$ stress time. Results for the devices not exposed to any PETS are also included in this figure. For the devices without PETS, there appears to be a "true" dose-rate sensitivity. Even 
after a $10^{6} \mathrm{~s}$ room temperature anneal, the radiation-induced $\mathrm{I}_{\mathrm{B}+}$ for the devices irradiated at $50 \mathrm{rad}\left(\mathrm{SiO}_{2}\right) / \mathrm{s}$ is 1.7 times smaller than $\mathrm{I}_{\mathrm{B}+}$ for the devices irradiated at $0.1 \mathrm{rad}\left(\mathrm{SiO}_{2}\right) / \mathrm{s}$. Increasing the time of the pre-irradiation burn-in quickly eliminates this difference between $\mathrm{I}_{\mathrm{B}+}$ at low and high dose rates with a room temperature anneal. To first order, ELDRS is reduced because the radiation-induced shifts in $\mathrm{I}_{\mathrm{B}+}$ at $0.1 \mathrm{rad}\left(\mathrm{SiO}_{2}\right) / \mathrm{s}$ are reduced. For thermal stresses equal to or greater than 10 hours at $175^{\circ} \mathrm{C}$, there is essentially no difference between the radiation-induced $\mathrm{I}_{\mathrm{B}+}$ at 0.1 and $50 \mathrm{rad}\left(\mathrm{SiO}_{2}\right) / \mathrm{s}$. This shows there is no "true" dose-rate sensitivity for these irradiation and anneal conditions.

We next examine radiation-induced changes in $I_{B+}$ for LM111s irradiated at 0.01 and $50 \mathrm{rad}\left(\mathrm{SiO}_{2}\right) / \mathrm{s}$ following a $175^{\circ} \mathrm{C}, 300$ hour stress. For the $0.01 \mathrm{rad}\left(\mathrm{SiO}_{2}\right) / \mathrm{s}$ irradiations, all the devices were irradiated in steps up to a total dose of $50 \mathrm{rad}\left(\mathrm{SiO}_{2}\right)$. For the $50 \mathrm{rad}\left(\mathrm{SiO}_{2}\right) / \mathrm{s}$ irradiations, different LM111s were irradiated up to a given total dose level and annealed at room temperature for a time equivalent to the low dose rate irradiation time at the same dose level. The results of this experiment are shown in Figure 9. At dose levels up to $10 \mathrm{krad}\left(\mathrm{SiO}_{2}\right)$, there are no "true" dose-rate effects. However, for higher total dose levels, the high dose rate irradiation plus room temperature anneal do not degrade $\mathrm{I}_{\mathrm{B}+}$ nearly as much as the low dose rate irradiation. The data in Figures 8 and 9 indicate that the differences in $\mathrm{I}_{\mathrm{B}+}$ at high total doses shown in Figure 6 can be attributed to a combination of "true" dose rate effects and time dependent effects.

\section{DisCussion}

The data in Figures 4 and 5 indicate that the radiation response of these LM111s are highly sensitive to preirradiation thermal stresses. That unbiased thermal stresses can induce changes in the charge transport and/or trapping properties of the oxides at the die level is consistent with previous work on MOS devices which suggests that the mechanism responsible for the PETS effect is bias independent [13]. Recall that previous work has shown that pre-irradiation elevated temperature stresses can cause increases in oxide-trap change buildup and decreases in interface-trap charge buildup [12]-[14], both of which act to reduce radiation-induced gain degradation in these types of substrate PNP transistors [6], [11]. We also note that for long stress times, PETS has effectively eliminated any "true" dose rate dependence for total dose up to $10 \mathrm{krad}\left(\mathrm{SiO}_{2}\right)$ in these devices. These results suggest there is a correlation between the mechanisms associated with the PETS and ELDRS effects in these devices.

The most commonly accepted model for ELDRS was proposed in 1996 by Fleetwood et al. [10] and amplified in 1998 by Witczak et al [7]. This model is based on the assumption that, at high dose rates, hole trapping in the bulk of the oxide overlying the base region occurs at metastable trap sites and produces space charge fields in the bulk of the $\mathrm{SiO}_{2}$. This space charge reduces both the amount of hole and
$\mathrm{H}^{+}$transport to the interface and the amount of hole trapping and interface trap buildup [7], [10]. During low-dose-rate exposures, holes can be released from the metastable trap sites during irradiation, the space charge field in the oxide is reduced, and holes and $\mathrm{H}^{+}$can transport easily to the interface where they may interact to degrade device operation.

Based on this model, we suggest a possible mechanism for the correlation between ELDRS and PETS effects. To understand the nature of this interaction, we observe that the application of PETS tends to reduce the amount of postirradiation gain degradation in these devices. This corresponds to an increase in oxide-trap charge and a decrease in interface trap charge in the base oxides of these PNP transistors [6], [11]. Hence, it seems likely that the elevated temperature stresses activate metastable trap sites in the bulk of the oxide (e.g., via the release of hydrogen that had previously passivated the site), thus increasing the range of doses and rates under which space charge fields are significant in the oxide [10], and consequently the region in which true dose rate effects are present in these devices. Moreover, the diffusive motion of some of these hydrogen species from the bulk of the oxide to the interface may lead to the passivation of interface trap precursors [21a], thereby reducing the probability of interface trap buildup. From previous work on MOS field oxides [13], the PETS effect was shown to be thermally activated with an activation energy of $\sim 0.38 \mathrm{eV}$. This activation energy is consistent with the diffusion of molecular hydrogen in $\mathrm{SiO}_{2}$ [24]. Thus, the diffusion of molecular hydrogen, or other hydrogen related species, may play a key role in the depassivation of the metastable trap sites in the base oxide and the passivation of the precursors at or near the base-emitter interface that lead to interface-trap charge buildup. However, regardless of the detailed microscopic mechanism for the ELDRS and PETS effects, present and previously data [13]-[16] show that it is strongly thermally activated, and therefore likely to be significant in many types of linear bipolar ICs.

As a final note, we have initiated a new set of experiments to provide additional insight into the mechanisms responsible for PETS and ELRDS. Specifically we are focusing on the different aspects of the thermal stress conditions (e.g., different types of ambients, ramp times, higher temperatures, and shorter times) that appear to be causing the changes in radiation response of the LM111s. While these experiments remain in progress, initial results show that different types PETS treatments can also be used to increase $\mathrm{I}_{\mathrm{B}+}$ degradation with irradiation, as shown in Figure 10. In this case, LM111s were exposed to a $450^{\circ} \mathrm{C}, 200 \mathrm{~s}$ stress, which is a much higher temperature than was used in this study, or that a device would likely see in use. (However, much higher temperatures can be experienced at short times during the packaging process, in many cases.) The increased post-irradiation $\mathrm{I}_{\mathrm{B}+}$ in Figure 10 is more consistent with the bimodal distribution reported in [17], and provides more evidence that PETS during and after packaging are responsible for the observed 
bimodal distribution. Moreover, the possibility that PETS can increase or decrease post-irradiation gain degradation is also consistent with the dual role of hydrogen in activating and passivating defects in $\mathrm{SiO}_{2}$ [25], [26], reinforcing the point that the interaction of hydrogen with defects in the bulk of the base oxide or at the emitter-base junction may play a key role in both ELDRS and PETS effects.

\section{HARDNESS ASSURANCE ISSUES}

These results can have significant implications for hardness assurance testing. The current ASTM hardness assurance test method used to estimate ELDRS effects in bipolar technologies requires the use of either low-dose-rate or elevated temperature irradiations [27]. Based upon the interaction between PETS and ELDRS suggested by our data, elevated temperature irradiations may not accurately estimate ELDRS in devices with a high degree of sensitivity to PETS effects. In fact, as we have shown, PETS can completely eliminate ELDRS for some irradiation conditions, thereby making it possible to considerably underestimate the effects of ELDRS. Hence, it is critical to evaluate the sensitivity of a linear bipolar IC to PETS before using elevated-temperature irradiation as an ELDRS test.

As a final note, the elevated temperature thermal cycles that die are exposed to during packaging can vary significantly as a result of differences in die attach techniques and package type (e.g., ceramic, plastic, or metal). Consequently, for technologies sensitive to the PETS effect, this might lead to significant variations in post-packaging irradiation response. Recall that others have observed significantly larger changes in the radiation response of devices packaged in plastic packages as opposed to ceramic packages [28]. Based on this work and the work of others [12]-[16], [28], it is clear any elevated temperature thermal cycles after fabrication (before, during or after packaging) can alter the radiation response of a technology sensitive to the PETS effect. Thus, to ensure devices function as required through the end-of-life in a system, hardness assurance testing of technologies sensitive to thermal cycles must account for all thermal cycles that devices are exposed to during packaging, reliability screens (e.g., burn-in), and system qualification and use, as emphasized in [14]. One way to do this is to subject the ICs to an elevated temperature preconditioning treatment that appropriately simulates all thermal cycles the devices will be exposed to through the end of life. But of course the most economical approach to system hardness assurance is to first determine if an IC is sensitive to PETS and/or ELDRS effects and, if so, find a replacement part that is not.

\section{SUMMARY AND CONCLUSIONS}

We have demonstrated that PETS (during and after packaging) can have a significant impact on ELDRS for LM111s. In some cases, the PETS actually eliminated ELDRS. These results suggest there is a correlation between the mechanisms associated with the PETS and ELDRS effects in these devices. Based on the model proposed in [7] and [10], we suggest a possible mechanism for the correlation between ELDRS and PETS effects that is associated with the activation of metastable trap sites in the bulk of the oxide by thermal stresses.

From a hardness assurance standpoint, we recommend all bipolar linear ICs should be evaluated to determine if they are sensitive to PETS effects before determining if they are sensitive to ELDRS effects. If a PETS sensitivity is detected, one should first try to find a suitable replacement part. If no replacement part is available, extreme caution should be taken to ensure the ICs will function as required throughout the lifetime of use. This may require carefully controlling all thermal stresses that the ICs may be exposed to before, during, and after packaging. In any case, one will need to account for these thermal cycles and determine their impact on radiation response of ICs at both high and low dose rates during qualification testing.

\section{ACKNOWLEDGMENT}

The authors thank Lew Cohn, Tom Turflinger, Dave Emily, and Ron Schrimpf for helpful technical discussions and Mike Maher for providing the samples. We would also like to thank Cathy Reber for packaging assistance.

\section{REFERENCES}

[1] E. W. Enlow, R. L. Pease, W. E. Combs, R. D. Schrimpf, and R. N. Nowlin, "Response of Advanced Bipolar Processes to Ionizing Radiation," IEEE Trans. Nucl. Sci. 38, 1342 (1991).

[2] R. N. Nowlin, D. M. Fleetwood, R. D. Schrimpf, R. L. Pease, and W. E. Combs, "Hardness Assurance and Testing Issues for Bipolar/BiCMOS Devices," IEEE Trans. Nucl. Sci. 40, 16861693 (1993).

[3] A. Wei, S. L. Kosier, R. D. Schrimpf, D. M. Fleetwood, and W. Combs, "Dose-Rate Effects on Radiation-Induced Bipolar Junction Transistor Gain Degradation," Appl. Phys. Lett. 65, 1918-20 (1994).

[4] A. H. Johnston, G. W. Swift, and B. G. Rax, "Total Dose Effects in Conventional Bipolar Transistor and Linear Integrated Circuits," IEEE Trans. Nucl. Sci. 41, 2427 (1994).

[5] D. M. Fleetwood, S. L. Kosier, R. N. Nowlin, R. D. Schrimpf, R. A. Reber, Jr., M. DeLaus, P. S. Winokur, A. Wei, W. E. Combs, and R. L. Pease, "Physical Mechanisms Contributing to Enhanced Bipolar Gain Degradation at Low Dose Rates," IEEE Trans. Nucl. Sci. 41, 1871-83 (1994).

[6] S. McClure, R. Pease, W. Will, and G. Perry, "Dependence of Total Dose Response of Bipolar Linear Microelectronics on Applied Dose Rate," IEEE Trans. Nucl. Sci. 43, 2544 (1994).

[7] S. C. Witczak, R. C. Lacoe, D. C. Mayer, D. M. Fleetwood, R. D. Schrimpf, and K. F. Galloway, "Space Charge Limited Degradation of Bipolar Oxides at Low Electric Fields," IEEE Trans. Nucl. Sci. 45, 2339 (1998).

[8] J. R. Schwank, P. S. Winokur, P. J. McWhorter, F. W. Sexton, P. V. Dressendorfer, and D. C. Turpin, "Physical Mechanisms Contributing to Device Rebound," IEEE Trans. Nucl. Sci. 31, 1434 (1984).

[9] D. M. Fleetwood, P. S. Winokur, L. C. Riewe, and R. L. Pease, "An Improved Total Dose Test for CMOS Space Electronics," IEEE Trans. Nucl. Sci. 36, 1963 (1989). 
[10] D. M. Fleetwood, L. C. Riewe, J. R. Schwank, S. C. Witczak, and R. D. Schrimpf, "Radiation Effects at Low Electric Fields in Thermal, SIMOX, and Bipolar-Base Oxides," IEEE Trans. Nucl. Sci. 43, 2537-2546 (1996).

[11] D. M. Schmidt, D. M. Fleetwood, R. D. Schrimpf, R. L. Pease, R. J. Graves, G. H. Johnson, K. F. Galloway, and W. E. Combs, "Comparison of Ionizing-Radiation-Induced Gain Degradation in Lateral, Substrate, and Vertical PNP BJTs," IEEE Trans. Nucl. Sci. 42, 1541-1549 (1995).

[12] M. R. Shaneyfelt, D. M. Fleetwood, J. R. Schwank, T. L. Meisenheimer, and P. S. Winokur, "Effects of Burn-In on Radiation Hardness," IEEE Trans. Nucl. Sci. 41, 2550 (1994).

[13] M. R. Shaneyfelt, P. S. Winokur, D. M. Fleetwood, J. R. Schwank, and R. A. Reber, Jr, "Effects of Reliability Screens on Charge Trapping," IEEE Trans. Nucl. Sci. 43 (3), 865-872 (June 1996).

[14] M. R. Shaneyfelt, P. S. Winokur, D. M. Fleetwood, G. L. Hash, J. R. Schwank, F. W. Sexton, and R. L. Pease, "Impact of Aging on Radiation Hardness," IEEE Trans. Nucl. Sci. 44, 2040-2047 (1997).

[15] R. L. Pease, M. R. Shaneyfelt, P. S. Winokur, D. M. Fleetwood, J. Gorlick, S. McClure, S. Clark, L. Cohn, and D. Alexander, "Mechanisms for Total Dose Sensitivity to Preirradiation Thermal Stress in Bipolar Linear Microcircuits," IEEE Trans. Nucl. Sci. 45, 1425-1430 (1998).

[16] C. Barillot, O.Serres, R. Marec and P. Calvel, "Effects of reliability Screening Tests on Bipolar Integrated Circuits During Total Dose Irradiation," IEEE Trans. Nucl. Sci. 45, 2638 (1998).

[17] J. Krieg, T. Turflinger, J. Titus, P. Cole, P. Baker, M. Gehlhausen, D. Emily, L. Yang, R. L. Pease, H. Barnaby, R. Schrimpf, and M. C. Maher, "Hardness Assurance Implications of Bimodal Total Dose Response in a Bipolar Linear Voltage Comparator," IEEE Trans. Nucl. Sci., Vol. 46, No. 6, 1627 1632 (1999).

[18] A. H. Johnston, B. G. Rax, and C. I. Lee, "Enhanced Damage in Linear Bipolar Integrated Circuits at Low Dose Rate," IEEE Trans. Nucl. Sci. 42, 1650 (1995).
[19] R. K. Freitag, and D. B. Brown, "Study of Low-Dose-Rate Radiation Effects on Commercial Linear Bipolar ICs," IEEE Trans. Nucl. Sci. 45, 2649 (1998).

[20] P. S. Winokur, F. W. Sexton, G. L. Hash, and D. C. Turpin, "Total Dose Failure Mechanisms of Integrated Circuits in Laboratory and Space Environments," IEEE Trans. Nucl. Sci. 34, 1448 (1987).

[21] D. M. Fleetwood, P. S. Winokur, and J. R. Schwank, "Using Laboratory X-ray and Co-60 Irradiations to Predict CMOS Device Response in Strategic and Space Environments," IEEE Trans. Nucl. Sci. 35, 1497 (1988).

[22] J. R. Schwank, D. M. Fleetwood, M. R. Shaneyfelt, P. S. Winokur, C. L. Axness, and L. C. Riewe, "Latent InterfaceTrap Buildup and Its Implication for Hardness Assurance," IEEE Trans. Nucl. Sci. 39, 1953 (1992).

[23] J. R. Schwank, D. M. Fleetwood, M. R. Shaneyfelt, and P. S. Winokur, "Latent Thermally Activated Interface-Trap Generation in MOS Devices," Electron Dev. Lett. 13, 203 (1992).

[24] D. L. Griscom, "Diffusion of Radiolytic Molecular Hydrogen as a Mechanism for the Postirradaition Buildup of Interface States in $\mathrm{SiO}_{2}$-on-Si Structures," J. Appl. Phys. 58, 2524 (1985).

[25] K. L. Brower, "Kinetics of $\mathrm{H}_{2}$ Passivation of $\mathrm{P}_{b}$ Centers at the (111) $\mathrm{Si}_{-} \mathrm{SiO}_{2}$ Interface," Phys. Rev. B 38, 9657 (1988).

[26] D. M. Fleetwood, M. J. Johnson, T. L. Meisenheimer, P. S. Winokur, W. L. Warren, and S. C. Witczak, " $1 / f$ Noise, Hydrogen Transport, and Latent Interface-Trap Buildup in Irradiated MOS Devices," IEEE Trans. Nucl. Sci. 44, 1810 (1997)

[27] R. L. Pease, L. M. Cohn, D. M. Fleetwood, M. A. Gehlhausen, T. L. Turflinger, D. B. Brown, and A. H. Johnston, "A Proposed Hardness Assurance Test Methodology for Bipolar Linear Circuits and Devices in a Space Ionizing Radaition Environment," IEEE Trans. Nucl. Sci. 44, 1981(1997).

[28] S. Clark, J. Bings, M. Maher, M. Williams, D. Alexander, and R. Pease, "Plastic Packaging and Burn-In Effects on Ionizing Dose Response in CMOS Microcircuits," IEEE Trans. Nucl. Sci. 42, 1607 (1995). 
M. R. Shaneyfelt et al., "Thermal-Stress Effects and Enhanced Low Dose Rate Sensitivity in Linear Bipolar Circuits," Submitted for publication in IEEE Trans. Nucl. Sci. (Dec. "00)

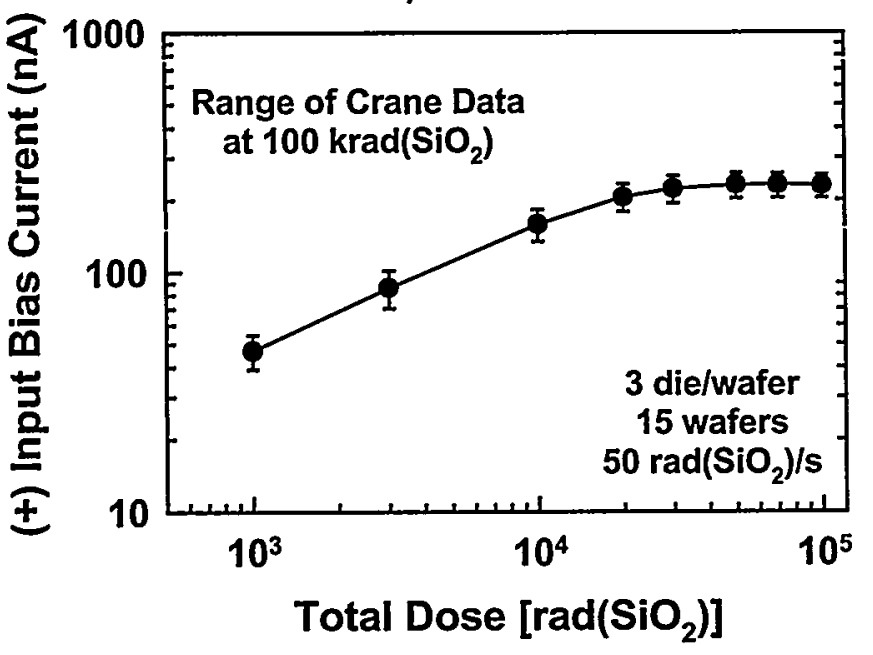

Figure 1: $\mathrm{I}_{\mathrm{B}+}$ versus dose for $\mathrm{LM} 111 \mathrm{~s}$ irradiated at $50 \mathrm{rad}\left(\mathrm{SiO}_{2}\right) / \mathrm{s}$. These LM111s were not subjected to any pre-irradiation elevated temperature stresses.

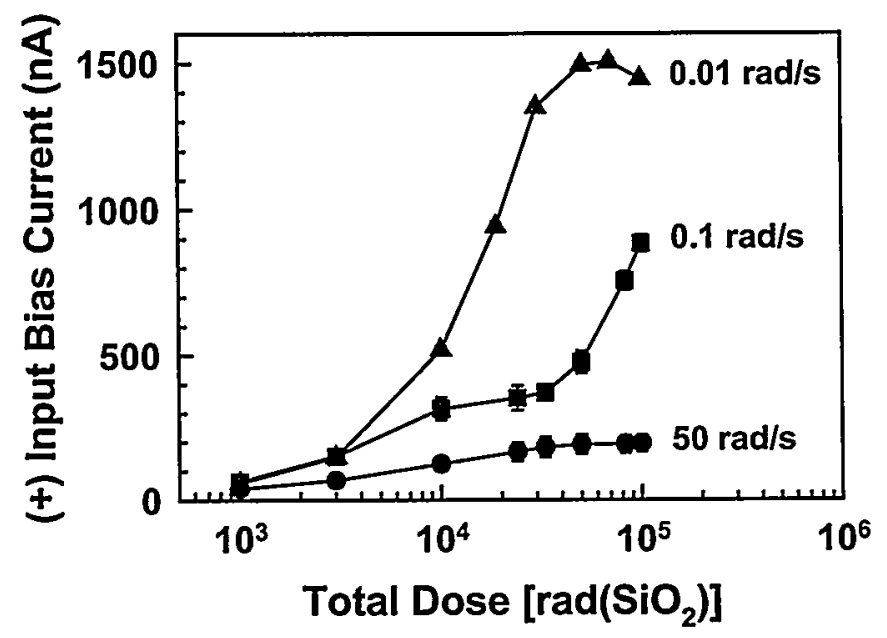

Figure 2: $I_{B+}$ versus dose for LM1 $11 \mathrm{~s}$ irradiated at $0.01,0.1$, and $50 \mathrm{rad}\left(\mathrm{SiO}_{2}\right) / \mathrm{s}$. These LM111s were not subjected to a preirradiation elevated temperature stress.

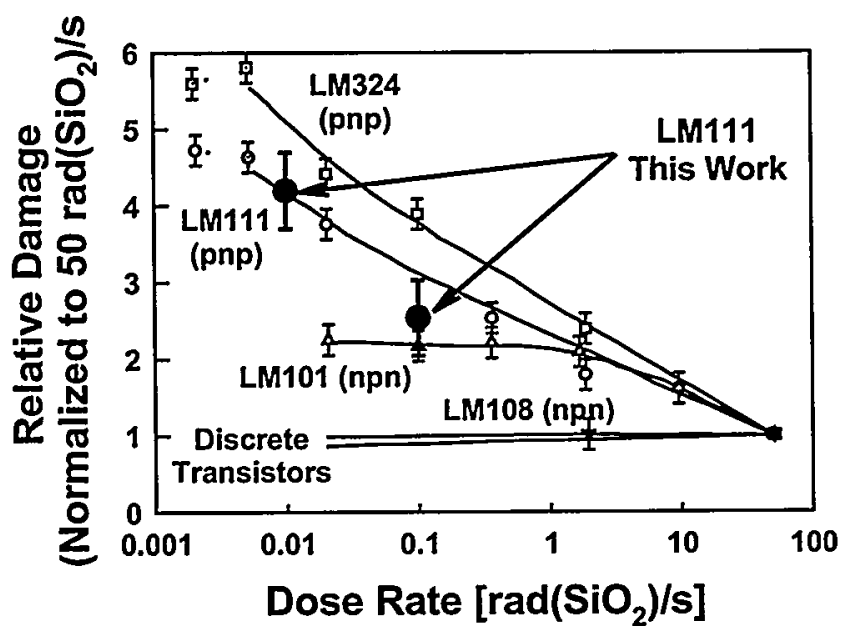

Figure 3: Relative damage versus dose rate after [4].

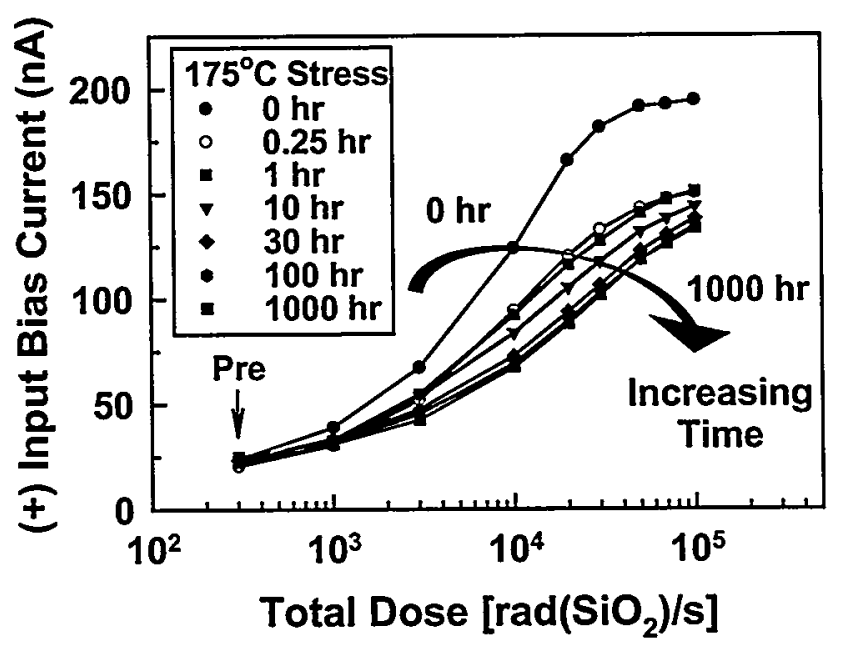

Figure 4: Average $I_{B+}$ versus total dose for $L M 111$ s exposed to pre-irradiation thermal stresses from 0 to 1000 hours. Devices were irradiated with all pins shorted at $50 \mathrm{rad}\left(\mathrm{SiO}_{2}\right) / \mathrm{s}$.

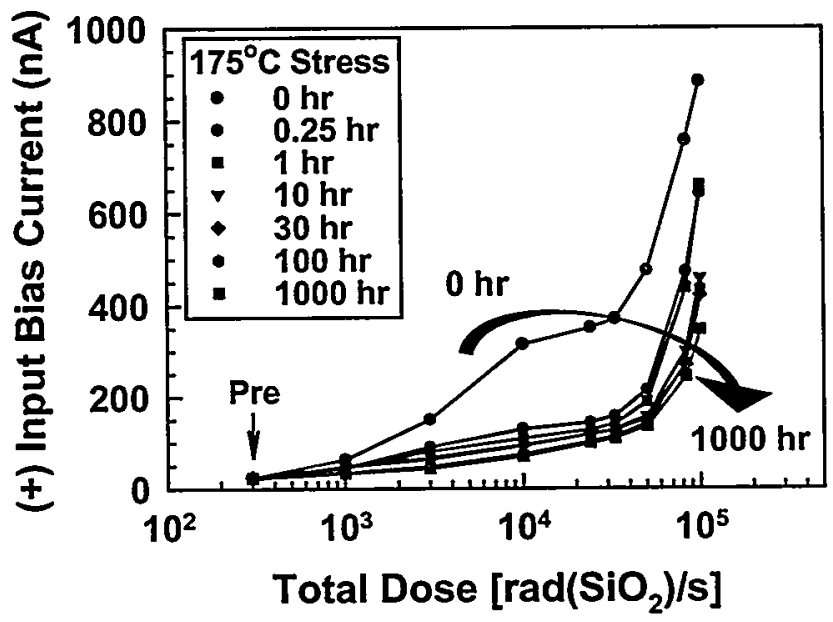

Figure 5: Average $I_{B+}$ versus total dose for LM111s exposed to preirradiation thermal stresses from 0 to 1000 hours. Devices were irradiated with all pins shorted at $0.1 \mathrm{rad}\left(\mathrm{SiO}_{2}\right) / \mathrm{s}$.

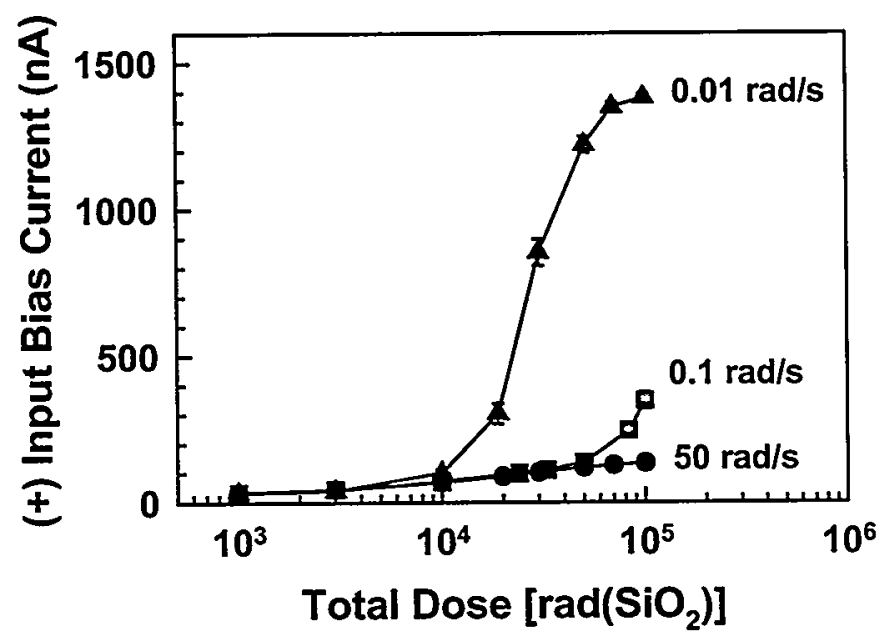

Figure 6: $I_{B+}$ versus dose for $L M 111$ s irradiated at $0.01,0.1$, and $50 \mathrm{rad}\left(\mathrm{SiO}_{2}\right) / \mathrm{s}$. These $\mathrm{LM} 111 \mathrm{~s}$ were subjected to a $175^{\circ} \mathrm{C}, 1000$-hour pre-irradiation elevated temperature stress. 


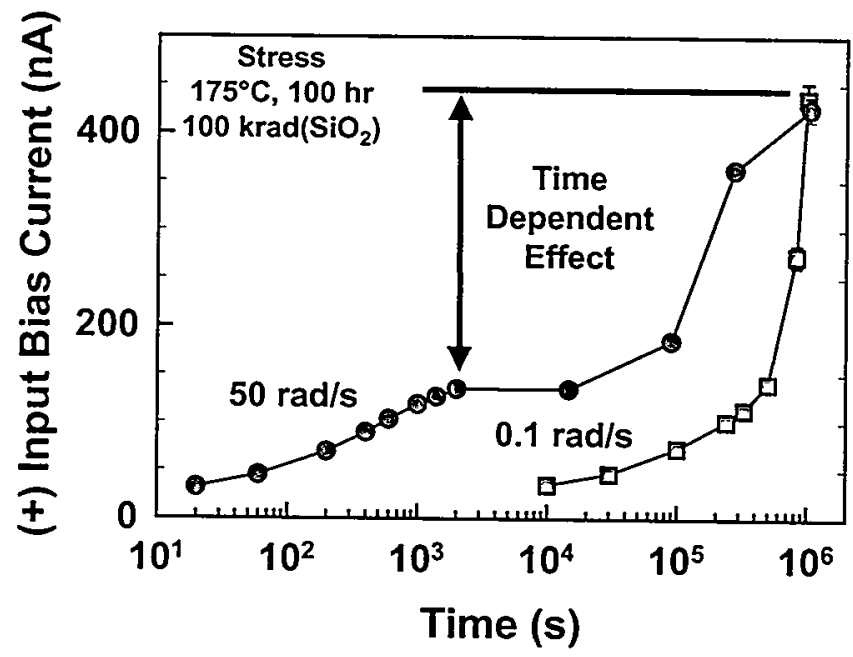

Figure 7: $\mathrm{I}_{\mathrm{B}^{+}}$after a $175^{\circ} \mathrm{C} 100$-hour burn-in versus dose for the LMII is. Devices were irradiated at 0.1 and $50 \mathrm{rad}\left(\mathrm{SiO}_{2}\right) / \mathrm{s}$. Following irradiation the devices irradiated at the high dose rate were annealed at room temperature with all pins shorted (red circles).

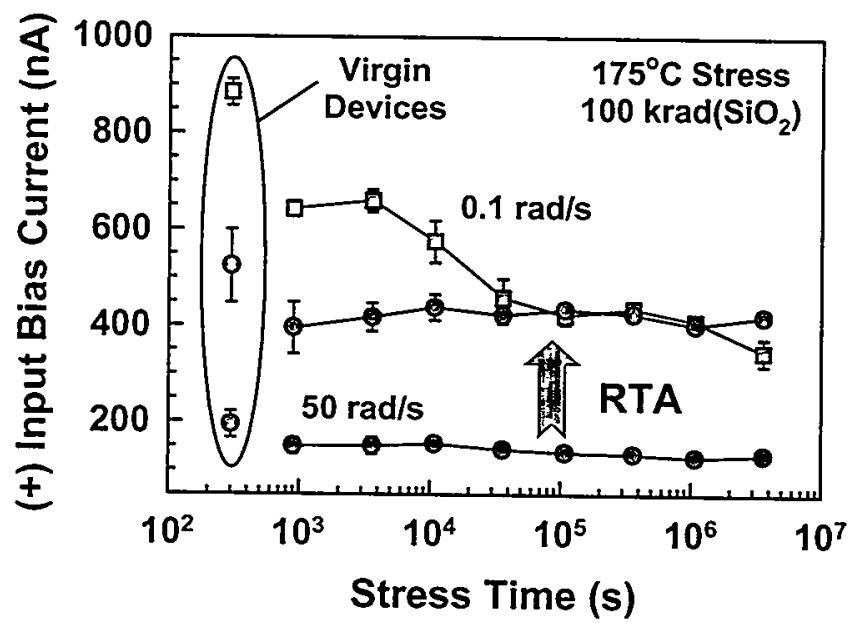

Figure 8: $\mathrm{I}_{\mathrm{B}^{+}}$versus burn-in time for the LM111s. Devices were irradiated to $100 \mathrm{krad}\left(\mathrm{SiO}_{2}\right)$ at 0.1 and $50 \mathrm{rad}\left(\mathrm{SiO}_{2}\right) / \mathrm{s}$ and annealed at room temperature with all pins shorted. The pre-irradiation burn-in was at $175^{\circ} \mathrm{C}$.

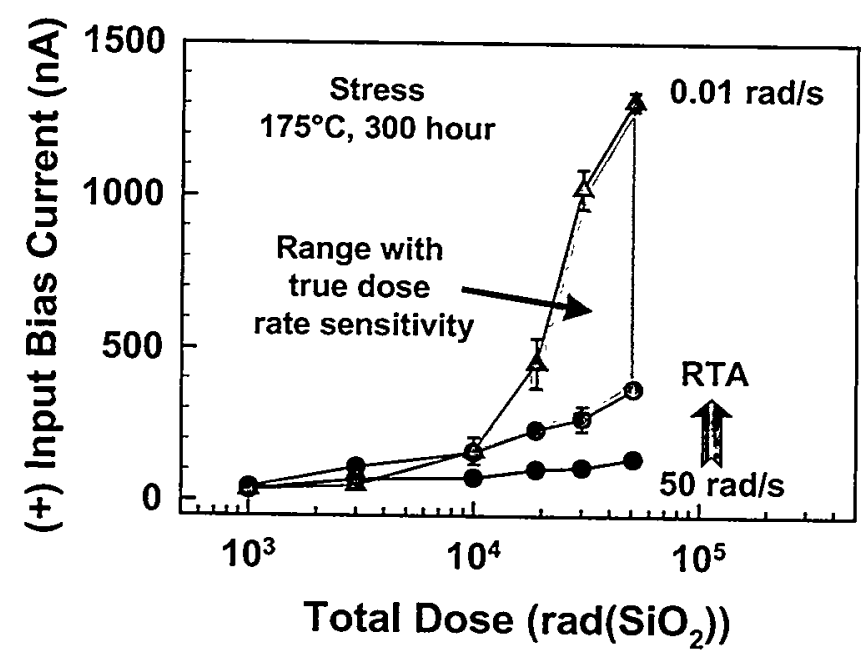

Figure 9: $\mathrm{I}_{\mathrm{B}+}$ after a $175^{\circ} \mathrm{C} 300$-hour burn-in versus dose for the LM111s. Devices were irradiated at 0.01 and $50 \mathrm{rad}\left(\mathrm{SiO}_{2}\right) / \mathrm{s}$. Following irradiation the devices were annealed at room temperature with all pins shorted.

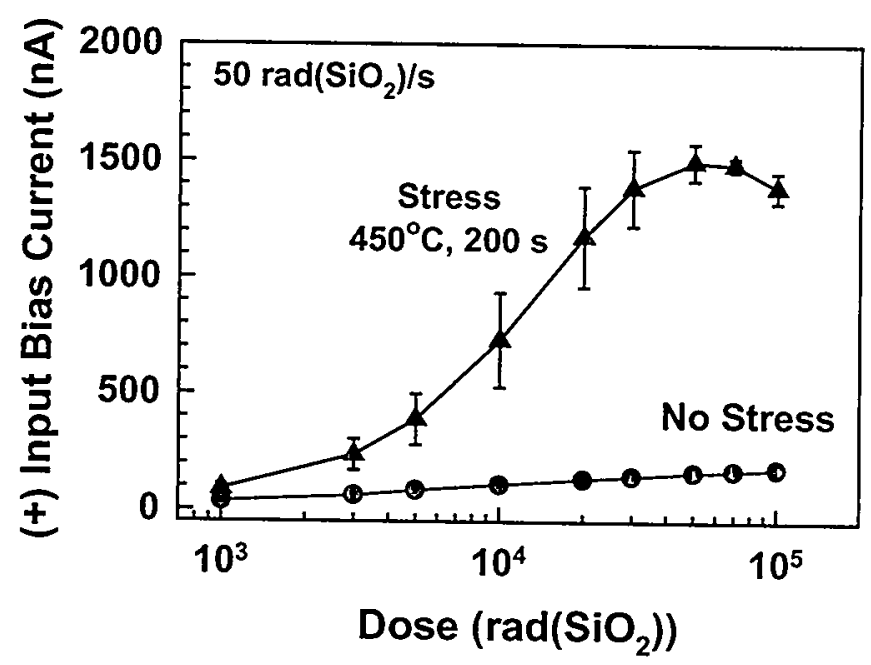

Figure 10: $\mathrm{I}_{\mathrm{B}+}$ versus dose for $\mathrm{LM} 111 \mathrm{~s}$ irradiated at $50 \mathrm{rad}\left(\mathrm{SiO}_{2}\right) / \mathrm{s}$. These $\mathrm{LM} 11$ is were subjected to a $450^{\circ} \mathrm{C}, 200$-s pre-irradiation elevated temperature stress. 